\title{
Governo Eletrônico em Ambientes Colaborativos Virtuais
}

\author{
Cintia Ramalho Caetano da Silva ${ }^{1}$, Thiago Cortat Tavares ${ }^{1}$, Ana Cristina Bicharra \\ Garcia $^{1}$, José Luiz Thomasseli Nogueira
}

${ }^{1}$ Instituto de Computação - Universidade Federal Fluminense (UFF)

Niterói, Rio de Janeiro - RJ - Brasil.

${ }^{2}$ Instituto Brasileiro de Geografia e Estatística (IBGE)

Av. República do Chile 500, 14 Andar - 20031-170 - Rio de Janeiro - RJ.

\{ccaetano, ttavares, bicharra\}@ic.uff.br ${ }^{1}$, jose.nogueira@ibge.gov.br ${ }^{2}$

\begin{abstract}
Currently there is a steady increase in the popularity of CVE's (collaborative virtual environment), and with it several initiatives has been proposed by many countries to implement e-government within these environments. Based on this context, this work focuses on the development of a virtual space to promote social interaction, dissemination of information, and electronic voting (secret, with only one vote per individual). It's goal is to verify the feasibility of applying Electronic Government's bodies under the scope of collaborative virtual environments. The example Electronic Government's body used on this work is the REUNI, a new Decree Law of the Federal Government which aims to reform the Brazilian federal universities. The CVE chosen for this work was Second Life, a virtual reality environment widely used around the world.
\end{abstract}

Resumo. Atualmente verifica-se um aumento crescente da popularidade dos CVE's (Collaborative Virtual Environment ou Ambientes Virtuais Colaborativos), e com isto diversas iniciativas de tem sido propostas por vários países na implantação de governo eletrônico dentro destes CVE's. Com base neste contexto, este artigo tem como objetivo o desenvolvimento de um espaço virtual para promover interação social, disseminação da informação e votação eletrônica, secreta e com voto único. O objetivo proposto é de verificar a viabilidade na transposição de instâncias de Governo Eletrônico aplicado sob o escopo de ambientes virtuais colaborativos. A instância de Governo Eletrônico abordado neste trabalho é o REUNI, novo decreto de Lei do Governo Federal que visa à reforma das Universidades Federais Brasileiras. O CVE escolhido para este trabalho foi o Second Life, um dos ambientes de realidade virtual amplamente difundido e utilizado em todo o mundo.

\section{Introdução}

Ambientes virtuais são espaços criados por computador que representam "mundos virtuais" onde os integrantes podem interagir entre si em tempo real. Segundo Espinha (2007), "um mundo virtual é basicamente composto por avatares, que são entidades controladas pelos usuários do jogo, e objetos virtuais controlados por computadores." 
Além da interação essas entidades podem entrar ou sair do mundo virtual a qualquer instante e mudar sua posição para qualquer parte dentro dos limites desse mundo. Recentemente, o sistema de mundo virtual que tem recebido considerável atenção, tanto por usuários quanto por estudiosos, é o Second Life.

Atualmente o Second Life vem sendo empregado por pessoas ou empresas para disponibilizar informações, marketing e vender tanto produtos virtuais como reais. Existem iniciativas de utilização deste ambiente em aplicações de governo, como: (a) $\mathrm{O}$ governo Português através de um projeto chamado e-Justice Centre, criou no Second Life um Centro de Resolução de Litígios, desenvolvido pelo Ministério da Justiça em parceria com uma Universidade de Lisboa [E-Arbitration-T 2007]; (b) O governo Sueco na tentativa de aquecer o turismo no país criou uma embaixada no Second Life, para servir informações sobre a cultura e história do país, bem como locais para visitação. [Second Life 2007]; (c) Na China, o governo está construindo o Distrito de Recreação Cibernética de Pequim onde se pretende ligar os consumidores diretamente as fábricas através do mundo virtual. [Mundo Linden 2007]

No Brasil, o governo eletrônico segue uma série de diretrizes e determinações com o objetivo de tornar o governo acessível ao cidadão, aprimorando a prestação dos serviços públicos e fortalecer a participação do cidadão pelo acesso a informação. Essas diretrizes estão descritas no E-PING (2005), que define um conjunto mínimo de premissas, políticas e especificações técnicas que regulamentam a utilização da Tecnologia de Informação e Comunicação (TIC) na interoperabilidade de Serviços de Governo Eletrônico. Uma das prioridades deste programa é a promoção da cidadania através da inclusão digital.

Ao se utilizar estas tecnologias para atender a necessidades do governo, criam-se novas estratégias que possibilitam modernizar a máquina administrativa e disponibilizam um novo canal para atender as necessidades do cidadão. Dessa forma, o presente trabalho justifica-se pela necessidade de utilizar aplicações mais próximas da realidade atual, e por possibilitar um maior realismo, para resolver problemas de Governo Eletrônico, que venha de certa forma aumentar o interesse do usuário pelo mesmo.

\section{Second Life}

O Second Life foi lançado em 23 de julho de 2003 pela Linden Lab, empresa norteamericana desenvolvedora de softwares localizada em São Francisco, Califórnia. Segundo Falco e Saar (2007), este ambiente é um "Metaverso", ou seja, um universo de realidade virtual que se assemelha ao universo real. Este universo virtual, denominado ciberespaço, segundo Levy (1996), resulta de uma virtualização dos computadores e é alimentado por todos que os utilizam. Já Falco (2007), afirma que o Second Life é sucesso, pois possui uma grande comunidade de relacionamentos, e também uma interface semelhante a um jogo 3D.

Segundo Patriota e Oliveira (2007), no mundo do Second Life as possibilidades são quase ilimitadas. Os usuários são denominados de residentes ou habitantes é têm autonomia para fazer o que quiserem na hora que lhes convém. Tamanha liberdade é vivenciada pelos residentes através de um avatar, conforme apresentado na Figura 1, uma representação digital do ser humano que deve ser criada por eles nos primeiros instantes de sua segunda vida no mundo paralelo. 


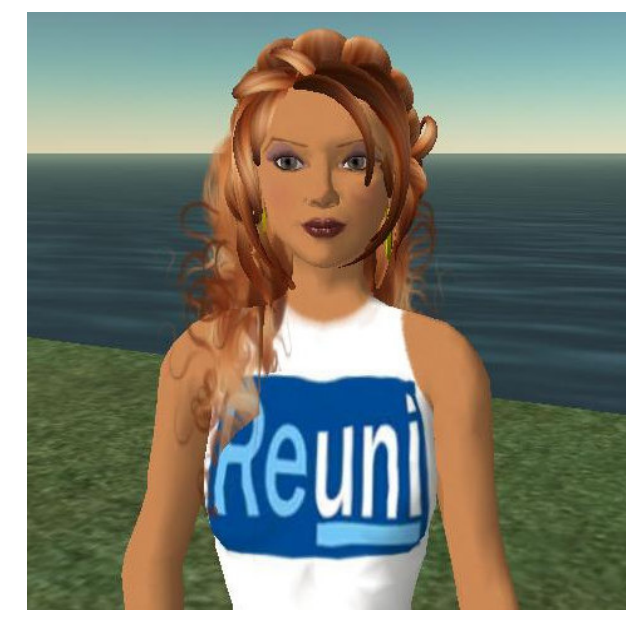

Figura 1. Avatar criado no Second Life

A interação no Second Life não ocorre somente entre avatares ou residentes, mas também com os objetos. O usuário pode criar seus objetos, casas, carros, móveis, roupas, etc., tudo é modelado em 3D. As localidades são chamadas de ilhas, por exemplo, a Ilha Recife é a representação da cidade de Recife no jogo. A Ilha Copacabana é a representação do bairro de Copacabana no Rio de Janeiro. Os cenários do ambiente são muito variados, e dependendo da temática e do criador da região.

O ambiente é muito extenso e para navegar nele é preciso de um mapa global ou local. Porém a distância não é um problema para os avatares, pois é possível voar e também se tele transportar para outro lugar ou ilha, ou até mesmo correr, abaixar-se, pular, entre outros inúmeros gestos disponíveis.

\subsection{Moeda}

O ambiente possui sua moeda própria chamada Linden Dollar (L\$), ganhando o mesmo nome da empresa que desenvolveu o jogo (Linden Labs). Apesar de não ter valor real direto, os Linden Dollar podem ser convertidos para qualquer moeda real e também é possível comprar e revender os Linden Dollars. Existe também a possibilidade dos usuários trabalharem, ou seja, obter empregos virtuais dentro do Second Life, ganhando assim seu dinheiro virtual. Segundo Second Life (2007), a moeda virtual tem valor flutuante em relação ao dólar americano e seu valor pode variar a qualquer momento.

\subsection{Jogabilidade}

A jogabilidade é muito ampla, podendo haver interação com quase todos os objetos do cenário, principalmente os objetos que fazem analogia ao mundo real, como revistas, jornais, carros, motos, televisão, por exemplo. $\mathrm{O}$ ponto forte da jogabilidade fica a cargo das inúmeras quantidades de ações que o usuário pode fazer no mundo virtual, por exemplo: dançar, nadar, voar, correr e trabalhar. A perspectiva da câmera é por default em terceira pessoa, podendo também ser modificada para primeira pessoa através do zoom da câmera. 


\subsection{Propriedade Intelectual}

Mesmo o Second Life sendo um ambiente virtual, ele não é desprovido de regulamentação jurídica. Isso ocorre devido a muitas das suas operações financeiras serem revertidas para a realidade. As criações intelectuais desenvolvidas dentro dele também possuem influência no mundo real, sendo, portanto passíveis de proteção. Dentre os direitos que merecem destaque no Second Life, existe a imagem, as marcas e as criações intelectuais, todas protegidas pela Lei $\mathrm{n}^{\circ}$ 9.279/96 - Lei de propriedade Intelectual. [ABIP 1996]

\section{Governo Eletrônico}

Segundo Ferreira (1999), Governo é definido como o sistema político pelo qual se rege um Estado, sendo este o responsável pelo fornecimento de informações e serviços ao cidadão. Segundo o Dicionário Aurélio (1999), cidadão é o indivíduo no gozo dos direitos civis e políticos de um Estado, ou no desempenho de seus deveres para com este. Ao verificar a relação destas duas entidades, deduz-se que cada cidadão possui um perfil e necessidades próprias perante o Governo.

Quanto à definição da entidade Governo Eletrônico (e-Governo), Moura (2004), afirma que são as estratégias utilizadas pelo governo, para uso dos recursos das TIC's, com o intuito de modernizar a máquina administrava e atender às necessidades do cidadão.

Ainda de acordo com Moura (2004), o Governo Eletrônico é uma das consequiências do crescimento e da automatização dos serviços e negócios eletrônicos ocorridos na última década. Neste domínio de aplicação, verifica-se atualmente que diversos governos provêm vários serviços e buscam a transparência da administração pública usando as tecnologias de informação existentes.

\subsection{REUNI}

Segundo o MEC (2007), o REUNI (Programa de Apoio a Planos de Reestruturação e Expansão das Universidades Federais), é uma política de expansão das Universidades Federais que tem como um dos seus objetivos é melhorar as condições necessárias para ampliação do acesso e permanência na educação superior. Este programa visa promover a entrada e permanência de jovens na faixa etária de 18 a 24 anos nas universidades, aumentado a oferta de vaga em pelo menos $30 \%$.

O REUNI possui como principal meta a elevação gradativa da taxa de conclusão média dos cursos de superiores para $90 \%$ e da relação de alunos/professor para 18, ao final de 5 anos. Pretende também um melhor aproveitamento do espaço físico, como também maior contingente de recursos humanos qualificados necessários para promover uma educação pública superior de qualidade.

Outro objetivo do REUNI é a democratização do ensino superior para estudantes de baixa renda, gerando a sua entrada na Universidade e garantindo sua permanência, e igualdades de oportunidades. Esse plano entra em vigor a partir de 2008 e terá sua viabilidade garantida pelo Ministério da Educação, mediante termos de metas a serem firmados pelo MEC e as Universidades participantes. 


\section{Desenvolvimento do Espaço REUNI}

Focando o desenvolvimento de um espaço para interação social, disseminação da informação e plebiscito virtual, o Espaço REUNI foi construído para realização dos experimentos no Second Life, especificamente na ILHA BRASIL SUL, e foi subdividido em quatro ambientes principais: o Quiosque do Governo, o Ambiente A FAVOR, o Ambiente CONTRA e o Ambiente de Votação. A temática do Projeto foi o REUNI, sendo assim todos os ambientes, com exceção da Votação, tinham o papel de dispor dados, idéias, informações e no caso dos ambientes CONTRA e A FAVOR, expor suas opiniões sobre este projeto do governo.

As informações sobre o REUNI foram repassadas aos usuários utilizando os mais diversos meios de interação, como cartazes, murais, músicas, imagens, folders, enquetes, fóruns virtuais de discussão, charges e quis sobre as propostas do projeto. A Figura 2 apresenta o prédio do Espaço REUNI.

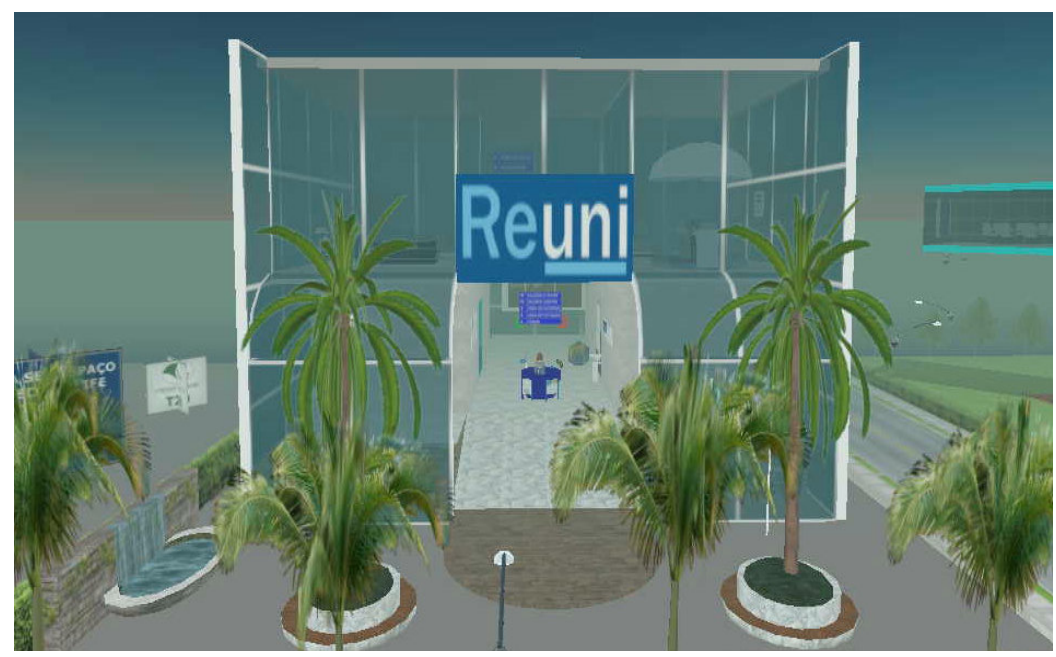

Figura 2. Prédio do REUNI na Ilha BRASIL SUL

\subsection{O Quiosque do Governo}

Este ambiente teve como propósito elucidar para o usuário ou avatar o conceito do REUNI, assim como suas propostas e diretrizes de uma maneira objetiva e imparcial, sem dar tendência a sua opinião contra ou a favor ao projeto. O Governo apresentou-se como uma entidade provedora de idéias e informações a população virtual presente.

\subsection{O Ambiente A FAVOR}

O ambiente A FAVOR apresentou-se como um local para obter informações relevantes, que tentarão conduzir o avatar a ser favor das propostas deste projeto governamental, promovendo as idéias, os ganhos e vantagens que serão concebidas para as Universidades Federais com a adoção do REUNI.

Através disto, disponibilizou-se dentro do ambiente, artifícios de interação como: painéis interativos, sons, folders, jogos, imagens, atendente virtual, entre outros. Na Figura 3 é mostrada uma parte da sala resultante do ambiente A FAVOR do REUNI. 


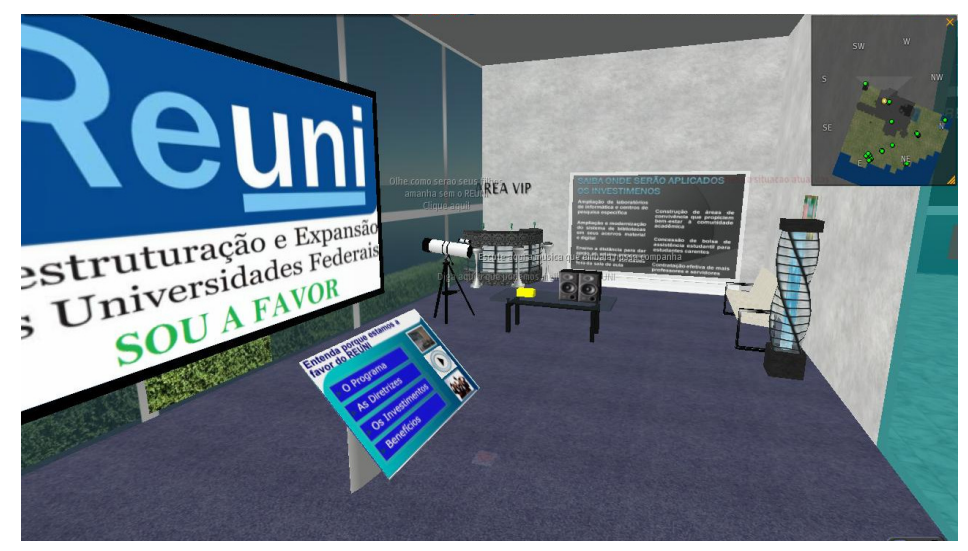

Figura 3. Ambiente A FAVOR

\subsection{O Ambiente CONTRA}

O ambiente CONTRA teve o papel de reportar todas as informações contrárias ao REUNI, questionando suas propostas, metas e diretrizes idealistas e muitas vezes pouco coniventes com a realidade atual das Universidades Federais. O foco deste espaço era passar aos visitantes a informação de que a reestruturação das Universidades Federais seria, futuramente, mais prejudicial do que vantajoso para o ensino superior das Entidades Federais. A Figura 4 mostra uma imagem referente ao ambiente CONTRA.

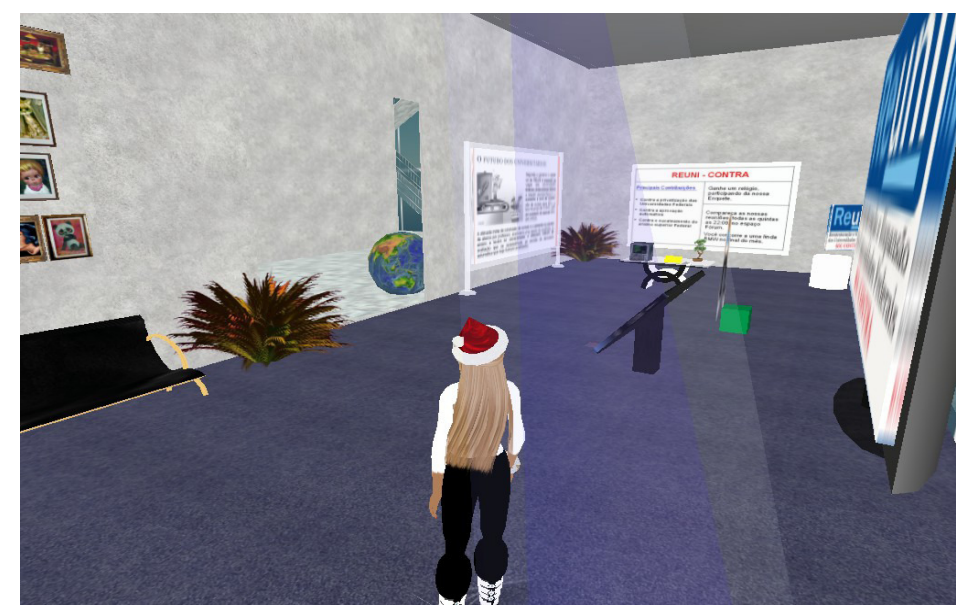

Figura 4. Ambiente CONTRA

\subsection{O Ambiente de Votação}

Na tentativa de desenvolver um ambiente de votação eletrônico virtual que fosse o mais perto da realidade possível, foi desenvolvido um espaço de votação virtual no Second Life composto de uma recepção, uma atendente, uma cabine de votação e uma urna. $\mathrm{O}$ ambiente de votação simula um sistema de votação eletrônico real, considerando as restrições que são determinantes para o funcionamento democrático deste processo.

$\mathrm{Na}$ recepção o avatar pode solicitar a ajuda da atendente ou simplesmente pegar a senha para assim dirigir-se a cabine de votação. Se a cabine estiver ocupada, a senha não é entregue, o avatar deve aguardar a cabine desocupar. Caso a cabine esteja desocupada, o avatar receberá a senha e poderá se dirigir a cabine de votação. Após pegar a senha o avatar tem 70 segundos para votar, senão sua senha expira e será 
necessário solicitar outra senha. A porta da cabine só abre se a cabine estiver desocupada. A Figura 5 apresenta o ambiente de votação.

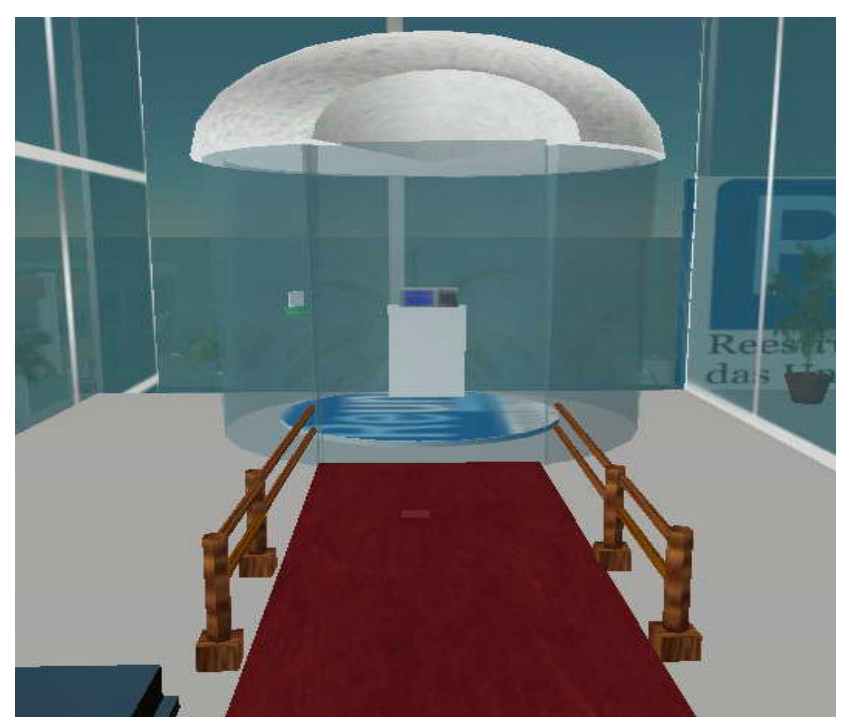

Figura 6. Cabine de Votação

Dentro da cabine o avatar pode ler o tutorial de votação, que ensina como votar, ou clicar sobre a urna para votar. Após votar, o avatar recebe um comprovante de votação, que é a confirmação de que ele votou, e ele não pode votar novamente. $O$ processo de votação implementado tem como objetivo desenvolver um sistema eletrônico de votação virtual que se aproxime ao máximo da realidade.

\section{Metodologia}

O experimento foi realizado de duas formas: a primeira, em um ambiente aberto e sem controle dos observadores, e a segunda, em um ambiente controlado com avaliadores pré-selecionados. A metodologia para os experimentos foi descrita a seguir.

\subsection{Experimento Aberto}

O público alvo para esse experimento foram os residentes da ILHA BRASIL SUL. O Espaço REUNI foi divulgado oficialmente através do envio de convites para todos os residentes da mesma. Logo após o envio dos convites, observou-se um grande número de visitas ao espaço. O experimento aberto tratou de acompanhar como os avatares já experientes no Second Life comportavam-se dentro dos ambientes criados para interação e como realizavam interagiam dentro desses ambientes.

\subsection{Experimento Controlado}

O experimento controlado foi realizado no laboratório de Pós-graduação da UFF (Universidade Federal Fluminense) e no ADDLabs (Laboratório de Pesquisas e Desenvolvimento em Inteligência Artificial da Universidade Federal Fluminense), que por sua vez foi preparado com antecedência para a realização dos testes.

O experimento controlado contou com a presença de dois grupos: os avaliadores, representados por professores, alunos e funcionários do Instituto de Computação da UFF, responsáveis por utilizar o Espaço REUNI construído no Second Life e expressar 
suas considerações sobre ele; E os observadores, representado pelos alunos responsáveis pela gestão do Projeto e pela apuração dos resultados dos testes.

Para este experimento os observadores tinham em mãos um formulário de controle da avaliação, no qual descreviam os problemas e dificuldades observados durante o teste. Já no caso dos avaliadores, os mesmos recebiam um cenário do ambiente onde constava um script de passos ou tarefas que deveriam realizar dentro dos ambientes. Cuidou-se também para que nenhuma citação sobre os testes, como o nome do avaliador ocorresse sem o seu consentimento explícito.

O processo de teste era iniciado solicitando que os avaliadores preenchessem um questionário de "Perfil do Usuário" e, logo após o preenchimento, era dada uma orientação sobre o propósito, objetivo e como proceder durante o teste. O tempo de execução utilizado foi medido de forma individual. Neste ponto, o observador procurou abster-se de qualquer interação com o avaliador, não expressando qualquer opinião ou comentário sobre o andamento do teste. A ajuda só era fornecida em caso de suporte ou quando o avaliador solicitava, ao final era solicitado ao avaliador que preenchesse um "Questionário de Satisfação do Usuário".

A implementação contou com um "Sistema Estatístico de Logs" rodando em background, onde capturava as entradas e saídas dos avatares nos ambientes citados anteriormente. O Sistema de logs rodou em um servidor externo ao Second Life, o nome do avatar e o tempo de permanência nos espaços, foram captados através de sensores de presença instalados em cada ambiente do prédio do REUNI.

\subsection{Técnicas de Avaliação}

Nesta seção será descrito as técnicas de construção e avaliação utilizada no ambientes que compõe o Espaço REUNI.

A primeira técnica utilizada foi o GOMS (Goals, Operators, Methods, and Selection Rules) é uma técnica de usabilidade que avalia o nível de aceitação da interface pelo usuário, levando em consideração o contexto de uso. Nielsen (1993), define o GOMS como um método que representa a estrutura cognitiva do usuário em termos de objetivos, operadores, métodos e regras de seleção. Será utilizado o GOMS como ferramenta para visualizar as interações sob a perspectiva do usuário.

Outra técnica utilizada foi o Storyboard, que é um desenho de como a interação será organizada. Segundo Souza et. al. (1999), os storyboards permitem a validação dos cenários e a elaboração de protótipos não operacionais para designs iniciais.

Finalmente, a Avaliação Heurística que é uma técnica onde um determinado avaliador externo faz sobre uma interação para de certa forma tentar prever futuros problemas, ela pode ser usada em qualquer fase do projeto através do avaliador que interpreta o desejo do usuário. Segundo Nielsen e Molich (1990), o avaliador procura problemas de usabilidade numa interface com o usuário através da análise e interpretação de um conjunto de princípios ou heurísticas. Ela é composta por dez diretrizes básicas, que são organizadas sob a forma de tabela, as chamadas Tabelas de Avaliação Heurística, e são aplicadas ao projeto como um todo. avaliação.

Cada ambiente do Espaço REUNI foi submetido a essas três técnicas de 


\section{Análise dos Resultados}

A análise dos resultados foi formada através dos dois experimentos realizados: o experimento controlado e o experimento aberto.

\subsection{Análise do Experimento Controlado}

Participaram do experimento aberto alunos, professores e funcionários da Universidade, um total de quarenta pessoas que colaboraram para este experimento.

Através do questionário de perfil dos usuários preenchido durante os testes, pôde-se observar que $79 \%$ dos avaliadores gostavam de jogos eletrônicos o que facilitou muito a aproximação ao sistema desenvolvido. $90 \%$ informaram que não utilizavam o Second Life e $40 \%$ nunca sequer ouviram falar sobre ele. Verificou-se que apenas $55,6 \%$ informaram que buscam informações sobre governo eletrônico na Internet, porém quando perguntados se já buscaram informações/serviços e quais foram estes, os mesmos responderam em $83 \%$ dos casos que buscavam se informar sobre a Declaração de Imposto de Renda. Percebeu-se então que a maioria das pessoas já utiliza os serviços de governo eletrônico na Internet, mas não possuem esta definição sedimentada em sua mente.

No questionário de satisfação do usuário, $85 \%$ mostraram-se satisfeitos e $15 \%$ insatisfeitos com a interação. A mesma porcentagem se aplica para quantidade de pessoas que acharam o ambiente de fácil aprendizado e bastante intuitivo, somando-se a isso, $90 \%$ conseguiram realizar todas as tarefas principais solicitadas aos avaliadores, que basicamente consistiam de entrar no ambiente do experimento, conhecer o REUNI, ler as propostas contra e a favor, concluir sua opinião e por fim votar.

Um padrão importante a ser destacado é que três dos usuários observados já possuíam opinião formada contra o REUNI, e devido a isto, recusaram-se a conhecer todo o local. Eles apenas preocuparam-se em ir em um dos espaços e depois na urna para votar. Com isso observou-se que os usuários, mesmo no mundo virtual, transferem suas emoções e convicções a ponto de não querer nem entrar no ambiente adverso as suas opiniões.

Por meio desse experimento, pôde-se demonstrar a facilidade de uma pessoa em incorpora-se na pele de um avatar e interagir em um mundo virtual realizando tarefas idênticas ao nosso meio físico e real. O Espaço REUNI mostrou-se agradável e fácil aos avaliadores, a maioria se sentiu bem confortável para realizar o experimento. Pode-se verificar que a interação dentro de um ambiente 3D pode ser possível a todos, independente de grau de instrução ou domínio do ambiente. Para que isto seja possível, os objetos devem expressar seu significado por si, fazendo a analogia com o mundo real, assim o usuário será capaz de saber exatamente o que deve fazer para realizar uma determinada tarefa.

\subsection{Análise do Experimento Aberto}

Através dos dados coletados foi verificado que os avatares do experimento aberto visitavam mais o ambiente do CONTRA. Isso ocorreu procedente ao fato de que no CONTRA não possuía uma porta, ao contrário do A FAVOR que existia a porta. Com isso, pode-se concluir que os usuários residentes do Second Life têm preferência por visitar locais onde podem ver o conteúdo antes de entrarem, isso também se aplicou ao 
segundo andar do prédio, onde mesmo com placas informativas e uma escada, os avatares tinham certa rejeição em subir para visitar.

Com relação à comunicação houve interação de $100 \%$ entre os avatares no canal de chat, que desejavam conversar e debater sobre o tema abordado, o REUNI. Uma limitação encontrada no Second Life é o fato de não ter como proibir que as pessoas conversem na área de votação, o chat é permitido em qualquer ambiente do Second Life.

$\mathrm{O}$ experimento aberto recebeu avatares dos mais variados tipos, e pode-se verificar que os mesmos não gostam de muitas regras e dificuldades para executar tarefas no ambiente. O simples fato de ter que pegar uma senha para votar, fez com que alguns usuários não votassem, e de certa forma não se interessassem pela votação em si.

\subsection{Análise Geral dos Resultados}

A análise geral dos resultados apresentou algumas similaridades nos dois tipos de usuários observados. Primeiro, observou-se que tanto usuários experientes, quanto o contrário, preferiram os painéis e cartazes com figuras e charges ao invés de painéis informativos onde havia somente textos. Os adereços oferecidos gratuitamente no ambiente, como camisas, bonés, óculos, tiveram um índice de receptividade relativamente aceitável.

Outro fato muito analisado foi a divergência do tempo médio gasto dentro de cada ambiente no Espaço REUNI de acordo com o tipo de usuário. Os avatares mais experientes passavam mais tempo nas salas do que os usuários considerados inexperientes. Verificou-se que os usuários mais experientes gastaram mais tempo por tentarem encontrar mais formas de interação existentes de cada ambiente, ao contrário dos usuários inexperientes que basicamente se preocuparam somente em obter as informações básicas sobre o tema REUNI e ao final votar.

Mesmo com as limitações que o Second Life apresenta, o sistema de votação eletrônico disponibilizado no espaço REUNI, conseguiu simular uma votação eletrônica bem próxima do mundo real. Sendo necessário observar alguns critérios de interação para assim torná-lo o mais próximo da realidade possível.

Por fim, em posse dos resultados obtidos neste trabalho foi possível verificar a adição de governo eletrônico em ambientes de realidade virtual, através do alto índice de satisfação, aprendizado, interação e facilidade de uso no ambiente, apurados tanto com usuários experientes quanto inexperientes.

\section{Conclusão}

A maior contribuição deste trabalho foi relacionar uma temática do domínio de governo eletrônico, com um ambiente de realidade virtual e mostrar que esta união é perfeitamente viável. A temática para utilização do governo eletrônico utilizado neste trabalho foi o REUNI, novo decreto de Lei que visa reformar as Universidades Federais e o ambiente de realidade virtual utilizado foi o Second Life.

Os dados demonstraram que os usuários avaliados tiveram facilidade em aprender e interagir com o novo espaço criado dentro do Second Life. Os experimentos realizados permitiram avaliar tipos diferentes de usuários, experientes e inexperientes, suas similaridades e diferenças, também como suas emoções e convicções que são transferidas do mundo real para o virtual. 
A plataforma Second Life funciona em parte, como uma nova alternativa de interface gráfica da Internet para o escopo de governo eletrônico. O trabalho, mais uma vez torna-se válido porque conseguiu transferir para o metaverso os conceitos de governo, responsabilidade, opinião, senso crítico e democracia.

Verificou-se com este estudo que o Second Life é um ambiente que permite implantar e discutir temas da área de governo eletrônico, provendo a interação amigável e intuitiva, tanto para o usuário acostumado com o ambiente quanto para o usuário menos experiente. Desta forma, foi possível disponibilizar serviços de governo em ambientes virtuais $3 \mathrm{D}$, com resultados satisfatórios.

\section{Referencias}

ABIP (1996). Associação Brasileira da Propriedade Intelectual. Lei $n^{0}$ 9.279/96. Disponível em: <http://www.abpi.org.br>. Acesso em: Dez. 2007.

Dicionário Aurélio Buarque de Holanda Ferreira. (1999). Editora: Nova Fronteira. ISBN: 8520910106. 3ª Edição. Ano: 1999.

E-Arbitration-T. (2007). Disponível em < http://www.e-arbitration-t.com/2008/02/28/ejustice-centre-odr-in-second-life/>. Acesso em: Nov. 2007.E-PING (2005). Padrões de Interoperabilidade de Governo Eletrônico. Documento de Referência Versão 1.0. 13 de julho 2005. Disponível em < https://www.governoeletronico.gov.br/acoes-eprojetos/anexos/E15_241e-PING\%20v1.0\%2013\%2007\%202005.pdf>. Acesso em: Dez. 2007.

Espinha. R. S. L.. (2007). Algoritmos distribuídos para ambientes virtuais de larga escala. Pontifícia Universidade Católica do Rio de Janeiro. PUC/RJ. 2007.

Falco, A. Jogos eletrônicos: do real ao virtual e vice-versa. Inovação Uniemp, Campinas, v. 3, n. 3, 2007. P. 55. Disponível em: $<$ http://inovacao.scielo.br/scielo.php>. Acesso em: Dez 2007.

Falco, A. e Saaar, J. F. (2007). Second Life como mídia de divulgação. Intercom Sociedade Brasileira de Estudos Interdisciplinares da Comunicação. XXX Congresso Brasileiro de Ciências da Comunicação - Santos - 29 de agosto a 2 de setembro de 2007. Pós Graduação em Comunicação Social da Universidade Metodista de São Paulo (UMESP).

Leyv, P. O que é virtual. São Paulo, Ed. 34, 1996. 160 p.

Moura, M. (2004). Governo Eletrônico e aspectos fiscais: a experiência Brasileira. Instituto de Pesquisa Econômica Aplicada. Rio de Janeiro, RJ: IPEA, 2004.

Mundo Linden (2007). Disponível em <http://www.mundolinden.com>. Acesso em: Dez. 2007.

Nielsen J. (1993). Usabilty Engineering, Morgan Kaufmann, Inc. San Francisco.

Nielsen, J. and Molich, R. (1990). "Heuristic evaluation of user interfaces." Proc. CHI'90 Conference on Human Factors in Computer Systems. New York: ACM, 1990, pp. 249- 256.

Patriota, K. R. M. e Oliveira, R. D. H. (2007). Second Life: experiência e consumo para uma nova abordagem da mensagem publicitária. $30^{\circ}$ Congresso Brasileiro de Ciências da Comunicação - INTERCOM 2007. 
Portal Governo Eletrônico do Brasil, Brasília, mai. 2004. Princípios e Diretrizes. Disponível em: <http://www.governoeletronico.gov.br>. Acesso em: Out. 2007.

Portal MEC (2007). Disponível em <http://portal.mec.gov.br/>. Acesso em: Dez. 2007.

Second Life (2007). Disponível em <http://www.secondlife.com>. Acesso: Nov. 2007.

Souza, C. S., Leite, J. C., Prates, R.O., Barbosa, S.D.J. (1999). Projeto de Interfaces de Usuário: Perspectivas Cognitiva e Semiótica. Anais da Jornada de Atualização em Informática, XIX Congresso da Sociedade Brasileira de Computação. Rio de Janeiro. Julho, 1999. 